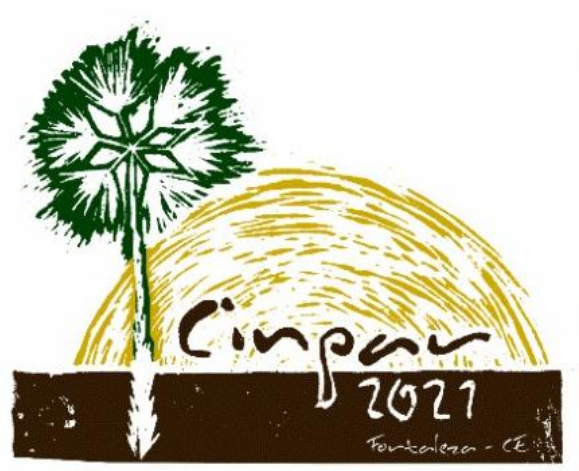

XVII Congresso Internacional sobre Patologia e Reabilitação das Construções

XVII Congreso Internacional sobre Patología y Rehabilitación de las Construcciones

XVII International Conference on Pathology and Constructions Rehabilitation

FORTALEZA (Brasil), 3 a 5 de junho de 2021

https://doi.org/10.4322/CINPAR.2021.145

\title{
Mechanical properties of traditional lime mortars
}

\author{
Anna TAFURO ${ }^{1}$, Marianna AURILIO ${ }^{2}$ \\ ${ }^{1}$ University of Campania "Luigi Vanvitelli", Aversa (CE), Italy, \{anna.tafuro; \\ marianna.aurilio\}@unicampania.it
}

\begin{abstract}
Large part of world Cultural Heritage is located in earthquake vulnerable areas and built with materials there available. The seismic events occurred in the course of the lives of these buildings have evidenced the strong dependence of the damages on the mechanical properties of the building materials. Recent seismic codes foresee for these buildings performance-based demands, so that the intervention materials' properties should be correctly calibrated. This is especially true for traditional structural mortars, particularly the lime-based ones. Mechanical tests on samples of structural mortars taken from existing buildings are rare, so that laboratory reproduction of ancient mortars based on traditional composition allow to detect reference values for restoration materials fulfilling code requirements.

This paper presents the results of a wide set of mechanical tests on a pozzolanic lime mortar, largely diffused in Southern Italy mortars. Three types of mortars and three different curing ages were tested and the results were analyzed, to assess the reliable use of traditional mortars in the restoration field.
\end{abstract}

Keywords: ancient masonry building; pathology.

\section{Introduction}

Lime mortars have been for centuries the materials to bond together bricks or natural stone blocks according the local availability to give rise to large part of the world architectural Cultural Heritage. Among the lime mortars the pozzolanic ones have a key role in all the Roman architecture and have been used in large part of the world following traditional compositions, since the Vitruvius treatise (Vitruvius, 1960) and until the XIX century treatises (Rondelet, 1827; Claudel et al., 1863).

The assessment of ancient structures, often located in earthquake vulnerable areas, is a complex process involving historical analyses, structural models, vulnerability evaluations and should be carried on with great care (Monaco et al., 2018; Guadagnuolo and Faella, 2020c). The simple knowledge of the actual geometry of the structure cannot be in fact sufficient if not appropriately connected to a rational coordination of the information about the whole past of the monument (Frunzio et al., 2019; Bergamasco et al., 2017 and 2018) together with the material properties (Monaco et al., 2014; Guadagnuolo et al., 2020b). The mix of natural pozzolan and lime has been the base of the mortars used in the course of history, so that rehabilitation interventions, especially those performed on Cultural Heritage (Gesualdo and Monaco, 2010; Buonocore et al., 2014), should involve the mechanical performances of the constituent materials and the reliability of their values should be referred to experimental tests (Guadagnuolo et al., 2020a). Unfortunately the drawing of sufficient mortar samples is a difficult task to be performed, given the small dimensions of the mortar joints. The reliable information available from in situ tests is relative to physical-chemical properties, while the strength properties can be derived from by suitable theoretical models developed for the entire masonry (Gesualdo and Monaco, 2015). The Vicat's studies (Vicat, 1818, 1856) are the first systematic researches on the mechanical properties of the lime mortars. They are still 
today a reference for experimental tests on lime mortar, but unfortunately the tests by Vicat were performed using different types sand only as an aggregate. The high quality mortars obtainable with the pozzolan have been included in other treatises of the time (Cavalieri San Bertolo, 1831) without the coherent organization and extension of Vicat experiments. In Southern Italy the pozzolanic mortars have been widely used during the century and are nowadays still in use, because of the large availability of this fine aggregate and the good quality mortars obtainable.

In the last century decades the use lime mortar as a building material has been strongly reduced in favour of cement mortars, even in the restoration field, where severe damages can be observed after several years since the intervention. The correlated traditional workmanship has been lost too. In recent years, given the improvements in the technology processes, there has been a sort of recovery of traditional techniques in the cultural heritage field (De Matteis et al., 2019; Monaco et al., 2020).

Lime mortars have been reconsidered for restoration, especially in combination with pozzolanic materials. On the other side, the development of numerical models for the analysis of masonry structures, in which the mechanical properties of mortar, in particular the tensile strength are essential features, whether for the in plane (Gesualdo et al., 2019, 2020) or the out of plane behaviour of masonry walls (Monaco et al., 2014; Guadagnuolo et al, 2009) has promoted deepening studies on these aspects (Monaco et al., 2018).

The mechanical properties of pozzolanic lime mortars are examined in this paper, taking into account the influence of different mix proportions respecting the classical treatises and different curing ages and conditions. The results can be the base for further discussion and reference for builders and designers in the restoration field, including improvements about the on-site curing conditions and time intervals. The main aim of the paper is in fact to give a contribute in the development of structural and restoration guidelines on traditional lime mortars.

\section{Laboratory tests}

The laboratory tests were performed using three types of lime and the traditional Neapolitan pozzolan. The three different mix proportions in weight are reported in Table 1. The water dosage in the three cases was chosen to obtain a workable mortar, to reproduce the yard workmanship (Monaco et al., 2021a).

Table 1 - Mix proportions

\begin{tabular}{|c|c|c|c|c|}
\hline Type & Binder type/Aggregate & Binder & Aggregate & Water \\
\hline A & Industrial hydrated lime/Pozzolan & 1.00 & 3.00 & 1.37 \\
\hline B & Industrial lime putty/Pozzolan & 1.00 & 4.17 & 1.06 \\
\hline C & Laboratory lime putty/Pozzolan & 1.00 & 4.11 & 1.13 \\
\hline
\end{tabular}

Tests were performed according to Italian standards developed in 1939 and still in use (RR.DD., 1939) and their minimum number and shape, together with the test types, are reported in Table 2.

Table 2- Number and shape of the specimens and type of test

\begin{tabular}{|c|c|c|c|c|c|}
\hline Shape & Type of test & Number & Length $(\mathbf{m m})$ & Depth $(\mathbf{m m})$ & Width $(\mathbf{m m})$ \\
\hline Prisms & Three point bending & 12 & 40 & 40 & 160 \\
\hline Small Cubes & Compression & 24 & 40 & 40 & 40 \\
\hline Large Cubes & Compression & 12 & 70 & 70 & 70 \\
\hline Briquette & Direct tension & 12 & 80 & 22.5 & 22.2 \\
\hline
\end{tabular}

The tests on large cubes were performed to investigate the influence of shape on the compressive strength, since in the tuff masonry heritage, largely diffused in Southern Italy, thick masonry joints are often present, and a reduction in the compressive strength was expected (Monaco et al., 2021b). 
Since in several constitutive models for masonry the tensile strength plays a key role (Gesualdo et al, 2019, 2020), direct tensile tests on briquettes have been performed, although these tests have not been recently sufficiently considered in the recent ASTM standards for repair of historic masonry (ASTM, 2017).
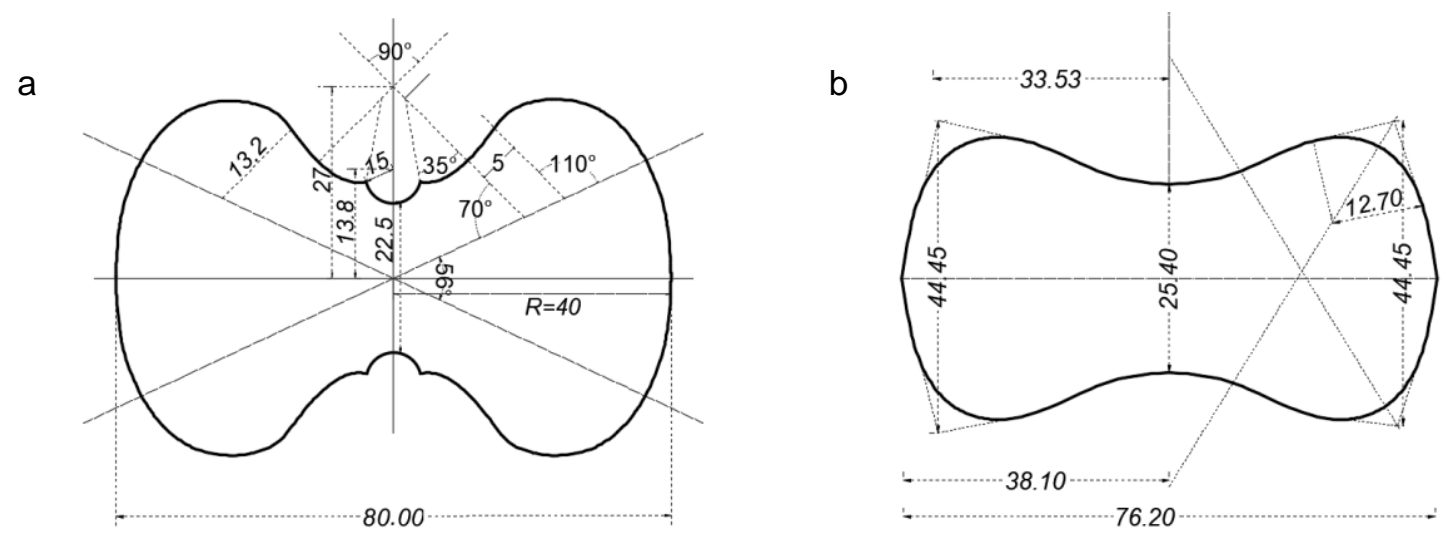

Figure 1. (a) Italian Standard Briquette (b) American Standard Briquette.

The investigated briquettes (RR.DD., 1939), whose dimensions are reported in Figure 1.a, are different from the standard ones (Army-C.O.E., 2001), in particular the minimum cross section is narrower, a true notch is absent, although the fracture cross section is more defined. Figure 1 presents a comparison of the two briquettes, while in Figure 2 the mould and the tension clips employed are reported.

a

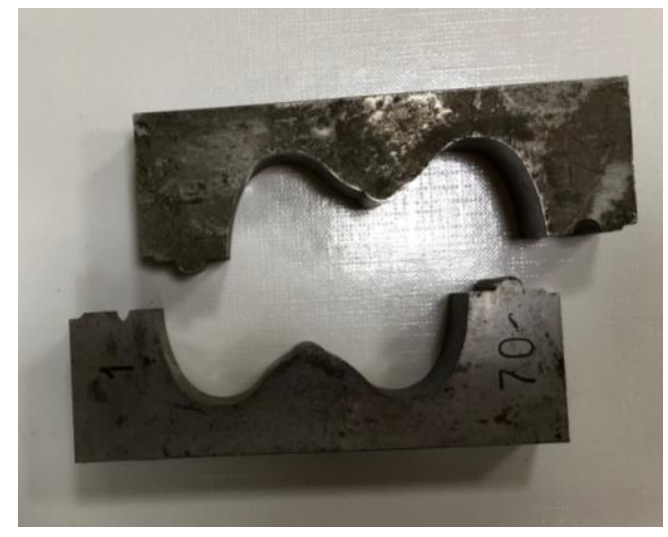



Figure 2. (a) Mold for the direct tensile tests (b) Tension clips.

The mixture was placed in the moulds at $80 \%$ relative humidity, this last level maintained until the demoulding after 24 hours curing. The process was completed placing the specimens in water to have three different curing times: 28, 60 and 180 days, since the mechanical properties of hydraulic mortars are strongly dependent on the curing age (Monaco et al., 2021a). All the testing operations were performed at room temperature, while water curing lasted until the testing time. For every curing age, a small part of the specimens was air-cured to investigate the influence of the curing type on the final strength. In all the presented diagrams the air-cured specimens (dashed lines in all the diagrams) presented, as expected, a very low strength compared to that of the water cured specimens at the same age (continuous lines). Moreover, the increasing rate is lower too, especially in the third curing interval (60-180 days). It must be noted that the increasing rate of strength in all the tests is lower in the third interval for A-type mortar too. The A-type mortar is in fact made, differently from the other two types, with powdered lime. Its strength rate increment is faster with respect to the other two binders, since lime putty needs several months to complete curing, so that long time curing tests have been performed. It must be noted that the in situ mortars have often several centuries age and restoration mortars are expected to last a long time too.

Figures 3 and 4 report the mean values of compressive strength of small cubes and large ones, respectively. As it can be noted, the values reported in Figure 3 are sensibly higher than those reported in Figure 4 and this can be referred to the different influence of the friction with the testing machine plates, 
which in the first case produces a higher confinement. In addition, the curing time influence on the compressive strength of small cubes gives as a result a higher slope.

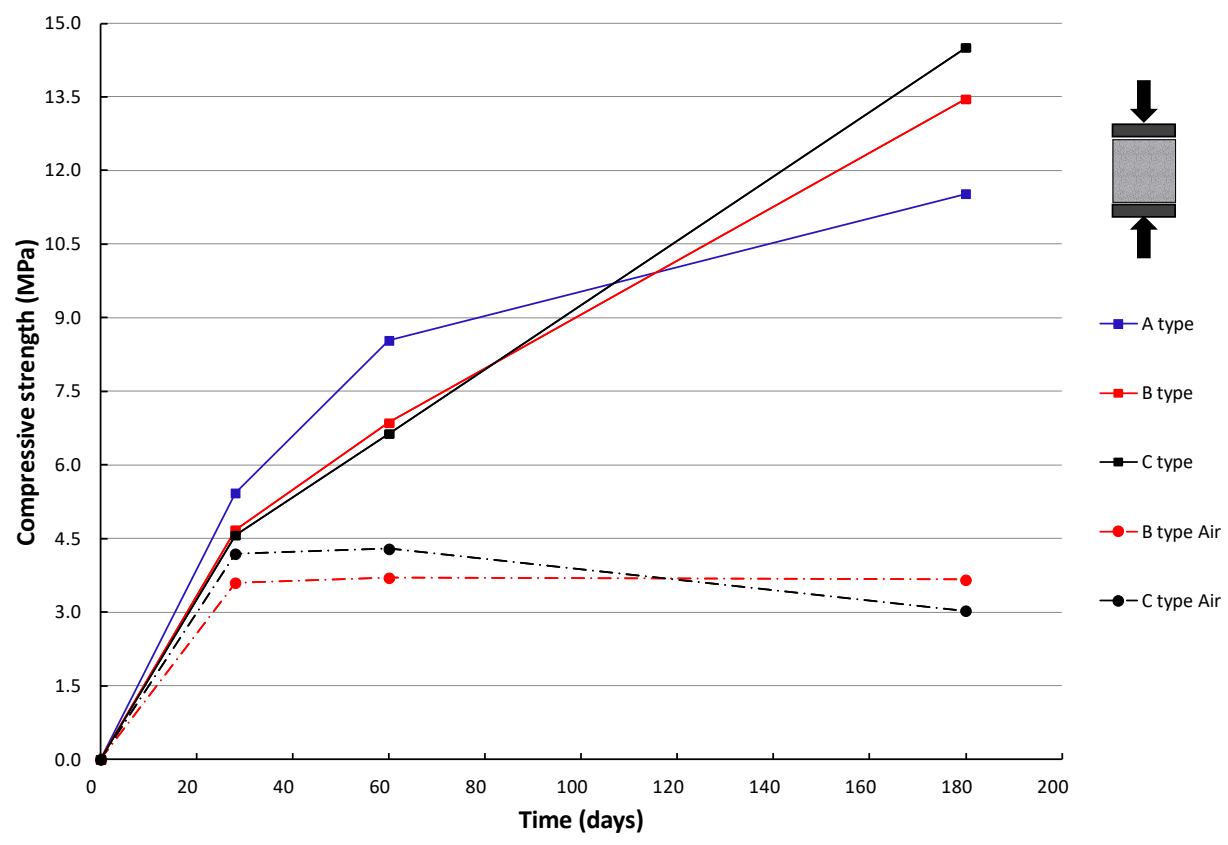

Figure 3. Mean compressive strength of $40 \times 40 \times 40 \mathrm{~mm}$ cubes versus curing time

Figure 5 and 6 report the mean values of indirect and direct tensile strength, evaluated respectively on standard prisms and briquettes. As it can be noted, the values of direct tensile strength are lower than those obtained by means of the three points bending test. Since the minimum cross sections of briquettes are very small, the only attention to be put in performing the tests is the laboratory manipulation to insert them in the testing machine. This is probably the reason of the actual distrust of the direct tensile tests. The low variation coefficient in all the test results performed in this campaign assures about the reliability of the tests.

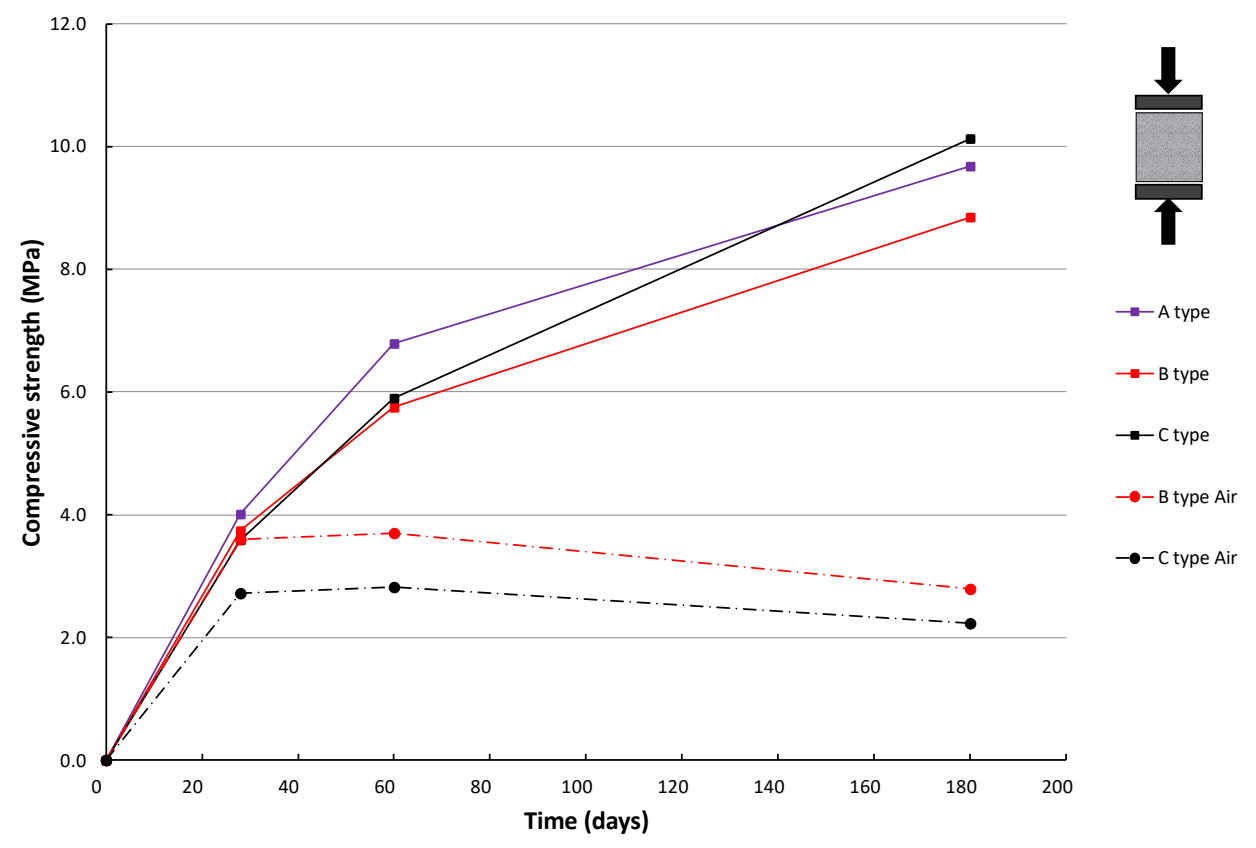

Figure 4. Mean compressive strength of $70 \times 70 \times 70 \mathrm{~mm}$ cubes versus curing time 


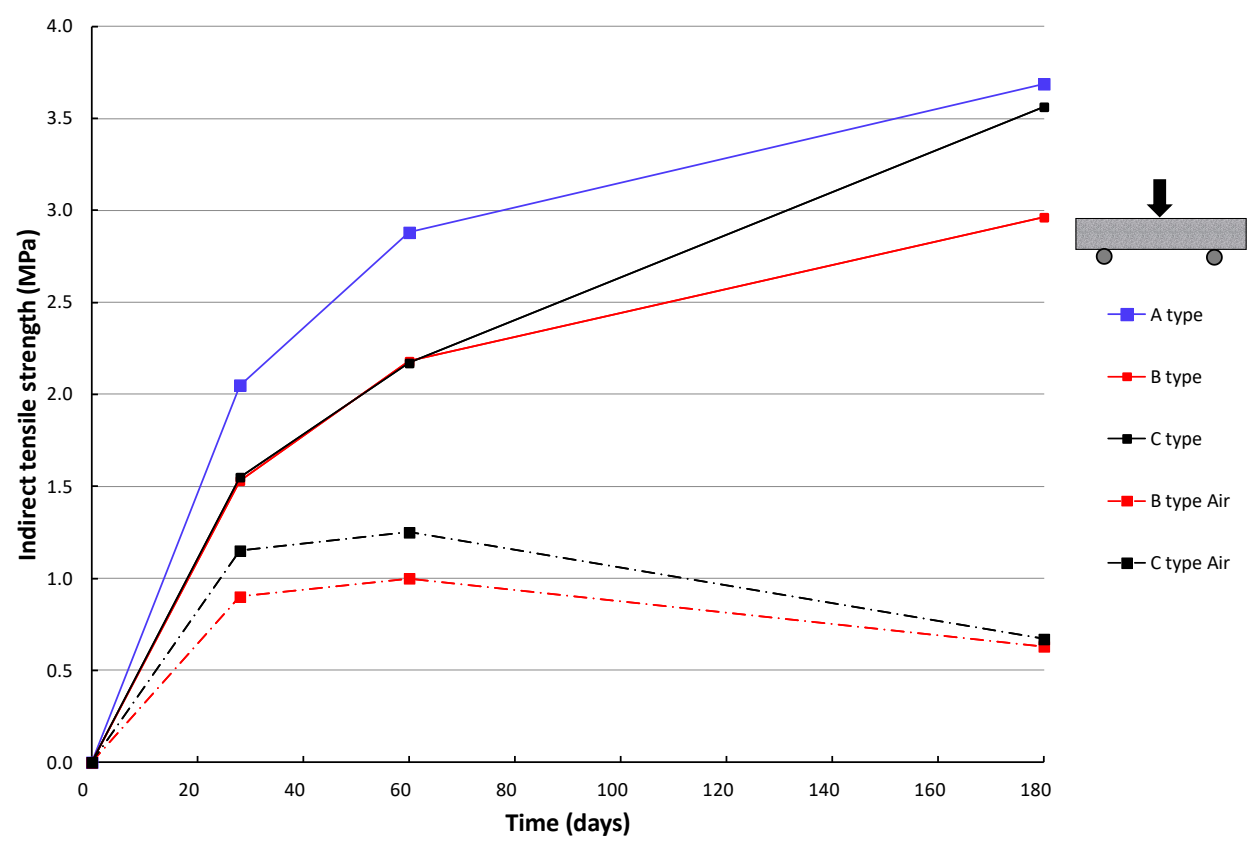

Figure 5. Mean indirect tensile strength (3-points bending) versus curing time

It must be noted that the mechanical performances of the three types of mortar tested by the authors are somewhat similar, with small differences due to the lime type. In particular, the laboratory slaked putty and the manufactured one, independently of the production process, give comparable results, as in the compression and the tension range. This can be a key aspect to be considered in the restoration field, when mortars have to be realized on the building site and often the time necessary to prepare a good quality lime putty is not available, so that a manufactured product resulting from a quality process is preferable.

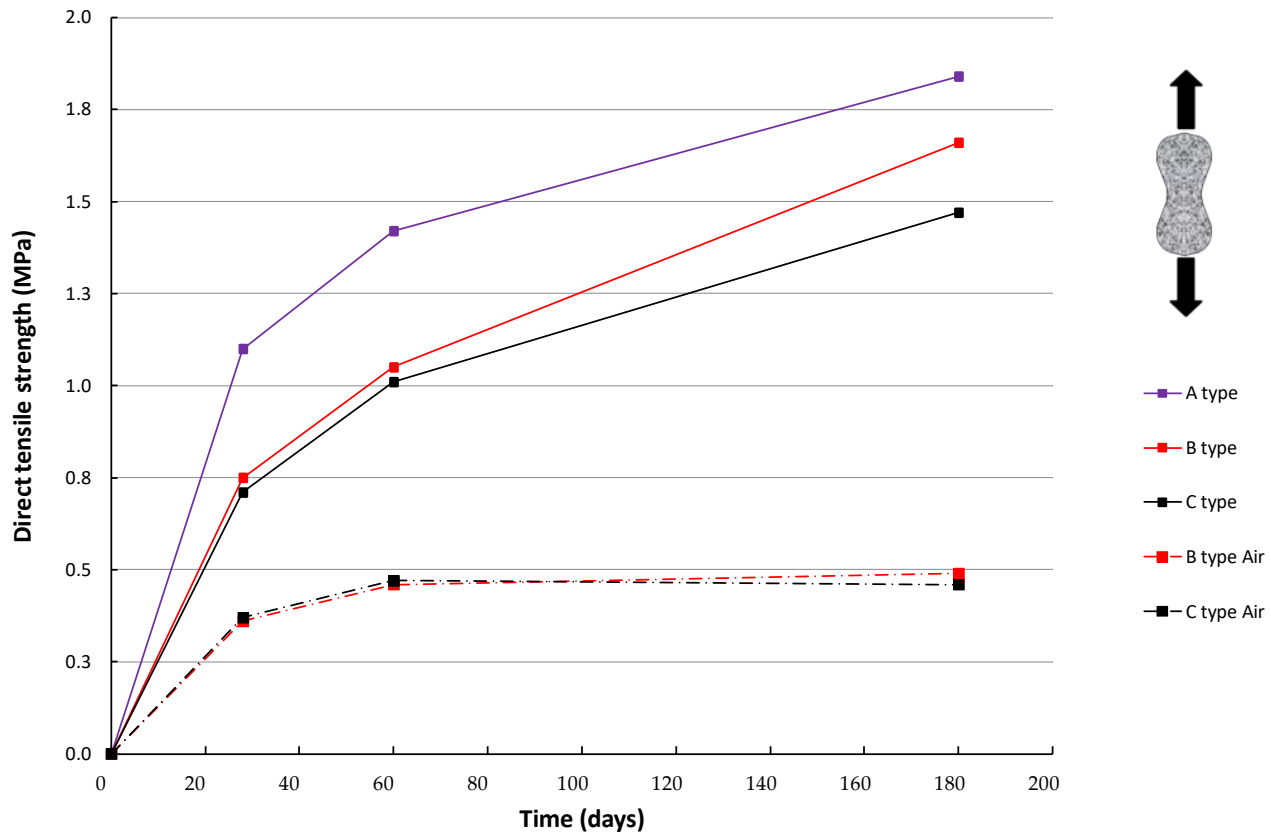

Figure 6. Direct tensile strength of briquettes versus curing time

The actual Italian code provisions for mortars require at least three tests performed at days age, regardless of binder quality. The strength increasing rate of pozzolanic lime mortars show that the actual 
curing time interval ( 28 days) is insufficient to evaluate their mechanical performance, so that a restoration code should take into account longer curing times.

\section{Conclusions}

The performance based seismic codes have evidenced the need of investigations about the strength properties of the building materials, and in particular the lime mortars. In several cases (frescoes or other decorations) the drawing of samples is a difficult topic to pursue, in large part of the cases the mortar samples are too small to be useful in mechanical tests. The only way to have information about mortar mechanical properties is their reconstruction with actual materials and similar compositions and properties, according to the mix proportions reported in the architectural treatises. In this paper the most diffused mortars in Southern Italy since ancient times are investigated. Experimental tests performed on pozzolanic lime mortars realized on purpose with three different lime qualities have shown that the mechanical performances are very respectable and respect the requirements of actual seismic codes. This is true as long as curing conditions and mix proportions are correct. In other words, curing conditions of hydraulic mortars should be respected even in the building site, so that prescription about their correct conservation should be reported in the restoration design. Standard flexural, compressive and tensile tests, together with compressive tests on large cubic specimens were performed. The strength values obtained in all the three examined mortar types are higher than the minimum required for structural mortars by Italian Seismic Codes and the increasing rate shown is higher in the third time interval, so that indications on the restoration codes about the optimal time interval after which the tests should be performed are required.

\section{Acknowledgments}

The authors acknowledge the contribute of the University of Sannio.

\section{References}

Army-C.O.E. CRD-C260-01, 2001. Standard Test Method for Tensile Strength of Hydraulic Cement Mortars ASTM C1713 - 17, 2017 Standard Specification for Mortars for the Repair of Historic Masonry

Bergamasco, I., Fortunato, A., Gesualdo, A., Iannuzzo, A., Monaco, M., 2017. A no-tension model for the analysis of combined masonry vaults, Atti del XXIII Congresso dell'Associazione Italiana di Meccanica Teorica ed Applicata, Salerno, Italy, September 4-7.

Bergamasco, I., Gesualdo, A., lannuzzo, A., Monaco, M., 2018. An integrated approach to the conservation of the roofing structures in the Pompeian domus, Journal of Cultural Heritage, 31, 141-151.

Buonocore, G., Gesualdo, A., Monaco, M., Savino, M.T. (2014) Improvement of Seismic Performance of Unreinforced Masonry Buildings using Steel Frames, in: Civil-Comp Proceedings: 106, B.H.V. Topping and P. Iványi eds., Civil Comp Press, Kippen, Stirlingshire, U.K., ISBN 978-1-905088-61-4.

Cavalieri San Bertolo, N., 1831. Istruzioni di architettura statica e idraulica, Mantova (in Italian).

Claudel, J., Laroque, L., 1863. Pratique de I'arte de construire, Parigi, Carilian - Goeuryet.

De Matteis G., Corlito V., Guadagnuolo M. and Tafuro A. (2019). "Seismic Vulnerability Assessment and Retrofitting Strategies of Italian Masonry Churches of the Alife-Caiazzo Diocese in Caserta, Int. J. Architectural Heritage, 14(8), 1180-1195.

Frunzio, G., Di Gennaro, L., Guadagnuolo, M., 2019. Palazzo Ducale in Parete: remarks on code provisions, Int. J. Masonry Research and Innovation, 4(1-2).

Gesualdo, A., Calderoni, B., lannuzzo, A., Fortunato, A., Monaco, M. 2020. Minimum energy strategies for the in-plane behaviour of masonry, Frattura ed Integrità Strutturale, 14(51), 376-385.

Gesualdo, A., Calderoni, B., Sandoli, A., Monaco, M. 2019. Minimum energy approach for the in-plane shear resistance of masonry panels, Ingegneria Sismica, 36(1), 42-53. 
Gesualdo, A., Monaco, M. (2010). Seismic vulnerability reduction of existing masonry buildings. Modelling of retrofitting tecniques. In: Urban Habitat Construction Under Catastrophic Events. vol. 1, p. 853-858, London, New York: CRC Press, Taylor \& Francis Group, ISBN: 9780415606851

Gesualdo, A., Monaco, M., 2015. Constitutive behaviour of quasi-brittle materials with anisotropic friction, Latin American Journal of Solids and Structures, 12(4), 695-710.

Guadagnuolo, M., Monaco, M. 2009. Out of plane behaviour of unreinforced masonry walls. In: Protection of Historical Buildings, 2, 1177-1180, London, New York: CRC Press

Guadagnuolo, M.; Aurilio, M.; Basile, A.; Faella, G. 2020a. Modulus of Elasticity and Compressive Strength of Tuff Masonry: Results of a Wide Set of Flat-Jack Tests. Buildings, 10, 84.

Guadagnuolo, M.; Aurilio, M.; Faella, G., 2020b. Retrofit assessment of masonry buildings through simplified structural analysis, Fracture and Structural Integrity, 14, 398-409.

Guadagnuolo, M.; Faella, G., 2020c. Simplified Design of Masonry Ring-Beams Reinforced by Flax Fibers for Existing Buildings Retrofitting. Buildings 2020, 10, 12.

Monaco M, Aurilio M, Tafuro A, Guadagnuolo M., 2021a. Sustainable Mortars for Application in the Cultural Heritage Field, Materials, 14(3), 598.

Monaco, M., Bergamasco, I, Betti, M. 2018. A no-tension analysis for a brick masonry vault with lunette, Journal of Mechanics of Materials and Structures, 13(5), 703-714.

Monaco, M., Calderoni, B., lannuzzo, A., Gesualdo, A., 2018. Behaviour of in-plane loaded masonry panels, Procedia Structural Integrity, 11, 388-393.

Monaco M., Faella G., Guadagnuolo M., 2021b. Analysis of pozzolanic mortars for restoration, International Journal of Conservation Science, 12(1), 41-50.

Monaco, M., Guadagnuolo, M., Gesualdo, A., 2014. The role of friction in the seismic risk mitigation of freestanding art objects. Natural Hazards, 73(2), 389-402.

Monaco, M., Iannuzzo, A., Tafuro, A., Gesualdo, A.,2020. Dynamic analysis of a Pompeian domus, Proc. EURODYN2020, EASD International Conference on Structural Dynamic, 2, 4922-4929.

Rondelet, J., 1827 Traité théorique et pratique de l'art de bâtir, impr. de Fain, Paris.

RR.DD. 11/06/1939, n. 2228-2235 "Norme per l'accettazione e per il collaudo dei materiali da costruzione" (in Italian)

Vicat, L.J., 1818. Recherches Expérimentales sur les Chaux de Construction, les Betons et les Mortiers Ordinaires, Paris: Académie Royale de Sciences.

Vicat, L.J., 1856 Traité pratique et theoritique de la Composition des Mortiers, Ciments et Gangues du Pouzzolanas, Paris: Ponts et Chausses.

Vitruvius, Ten books on architecture, M.H. Morgan, Trans, Dover Publications Inc., New York, 1960. 